\title{
Replication Note \\ Regret of Action or Regret of Inaction: Examining Divergent Regret Patterns for Experiential and Material Gifts
}

Aminreza Shiri and Ahmet Ekici*

Bilkent University, Turkey

\begin{abstract}
We replicate Rosenzweig and Gilovich's (2012) study on "differential regrets for experiential and material purchases," according to which people experience regret of action (buyer's remorse) for material purchases and regret of inaction (missed opportunity) for experiential purchases. Our results suggest that the original findings can be extended to gift giving context. Furthermore, we demonstrate that perceived subjective economic value of gifts explains the different forms of regrets (regret of inaction vs. regret of action) elicited by experiential and material gifts.
\end{abstract}

\section{Introduction}

$\mathrm{T}$ HE research comparing experiential goods (i.e. an event one lives through) with material items (i.e. objects to be kept in one's possession) suggests that experiential goods are superior to material goods in several ways. For example, compared to possessions, experiences lead to greater well-being and happiness (Dunn et al. 2011; Van Boven and Gilovich 2003) and in the eyes of consumers the money spent on life experiences carries more economic value (Subjective Economic Value) than material goods (Guevarra and Howell 2015; Van Boven and Gilovich 2003). Furthermore, Rosenzweig and Gilovich

*Mr. Aminreza Shiri, Bilkent University, Faculty of Business Administration, Ankara, Turkey'aminreza.shiri@bilkent.edu.tr. Dr. Ahmet Ekici, Bilkent University, Faculty of Business Administration, Ankara, Turkey.

MS submitted on 17 November 2016; final version received 29 June 2017

Replication Editor: Donald Lehmann ISSN 2326-568X; DOI 10.1561/107.00000044

(C) 2017 A. Shiri and A. Ekici 
(2012) demonstrated that consumers are more likely to experience a regret of inaction (missed opportunity) for their experiential purchases and regret of action (buyer's remorse) for their material purchases (for self-consumption). They explain that these different forms of regrets are driven by the fact that experiential purchases tend to be less interchangeable (more singular and unique) than material purchases. Interestingly, their results suggest that simply by highlighting the experiential aspects of material items consumers will be less likely to experience buyer's remorse. Rosenzweig and Gilovich's findings are of great importance for marketers, in that regret plays a crucial role in post-purchase evaluation and how consumers will try to avoid regret in their future purchases (Zeelenberg and Pieters 2007). Are Rosenzweig and Gilovich's findings valid in gift giving context? In the billion-dollar gift industry, predicting the type of regret that gift givers may experience could potentially be crucial information for marketers and their advertising strategies. Negative feedback such as buyer's remorse could potentially have a negative influence on the future buying behavior of a gift giver and may lead the gift giver to reduce gift buying in order not to experience such regrets.

To answer the above question, we replicated and extended Rosenzweig and Gilovich's (2012) study in the gift giving context, in which the purchase will be consumed by someone other than oneself. To further extend their results, we measured the subjective economic value attached to experiential and material gifts by asking participants to "evaluate the wisdom of their purchase from an economic standpoint" (Van Boven and Gilovich 2003, p. 1194). We anticipate that the SEV of gifts could potentially explain the different types of regrets elicited by experiential and material goods, in that the money spent on experiential goods are considered to be more well-spent than the money spent on material goods (Guevarra and Howell 2015; Van Boven and Gilovich 2003).

We conducted three experiments to replicate and extend the original results. Study 1 was designed to test whether people demonstrate the regret of action for material gifts and regret of inaction for experiential gifts. In study 2 we tested the results of study 1 in a more controlled setting and examined whether results from study 1 "extends from the self to judgments about others" (Rosenzweig and Gilovich 2012, p. 217). Lastly, study 3 was designed to investigate the mediating role of Subjective Economic Value on different types of regrets elicited by material and experiential gifts. See Table 1.

\section{Study 1}

\section{Method}

One hundred and eleven $\left(52 \%\right.$ female; $\left.M_{\text {Age }}=21.41, \mathrm{SD}=1.98\right)$ students were recruited from Bilkent University and were randomly assigned to either the experiential $(N=57)$ or material $(N=54)$ gift condition. They first read 
Table 1: Comparison of the replication paper's findings with those of the original paper.

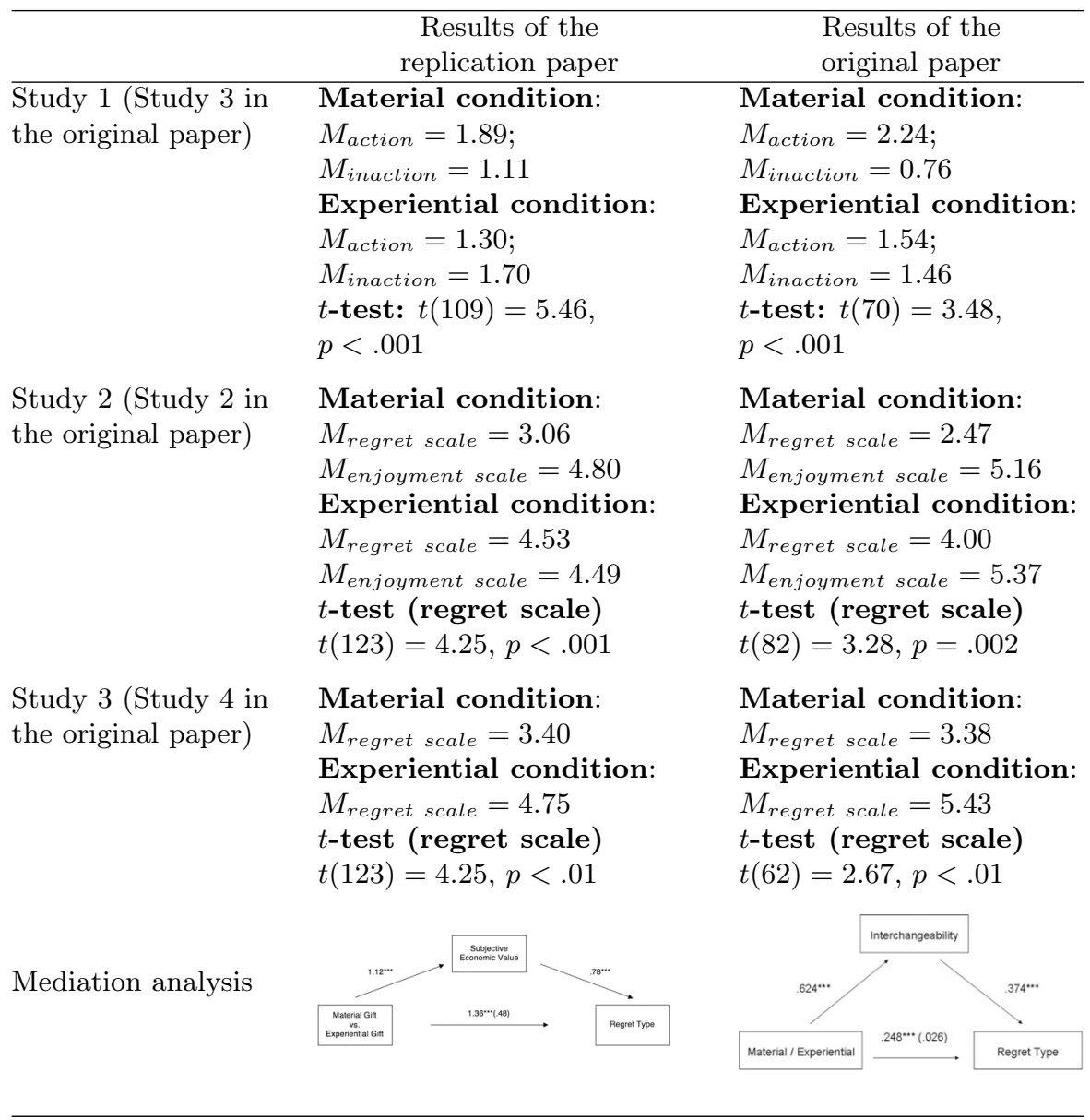

a brief definition of a material gift ("tangible objects to be kept in recipient's possession") or experiential gifts ("a life experience/event that recipient lives through") after which they were presented with the following text on regret of action or inaction:

Occasionally, we make decisions that we end up regretting. Sometimes, for example, we spend money on some gifts and afterwards realize the purchase was a mistake, and we end up regretting the action we took. Other times we don't give a [material/ 
experiential] gift that we had thought about; afterwards we realize that we should have given the gift and we end up regretting our inaction.

Depending on the condition (experiential vs material) to which participants were assigned, they were asked to list either three specific experiential or material gift regrets that they have experienced as a gift giver. They were then asked to label each of the regrets they listed with an A for action and an I for inaction. Lastly, to control for the potential effect that the closeness of the gift giver and recipient might have on the patterns of regrets, we asked them to rate how close and connected they were at the time they gave the gift to the recipient, for each of the three gifts they listed $(1=$ feel extremely distant and disconnected, $7=$ feel extremely close and connected).

\section{Results and Discussion}

A one-way ANCOVA, controlling for age $(F[1,107]=.18, p=.66)$ and gender $(F[1,107]=.98, p=.32)$, demonstrated that there was significant difference on regret types across the two gift conditions $(F[1,107]=29.28$, $p<.001)$. The mean number of regrets of action was significantly higher $(t(109)=5.46, p<.001)$ for participants in the material gift condition $\left(M_{\text {action }}=1.89\right)$ than in the experiential gift condition $\left(M_{\text {action }}=1.30\right)$. In contrast, participants in experiential condition $\left(M_{\text {inaction }}=1.70\right)$ compared to participants in material condition $\left(M_{\text {inaction }}=1.11\right)$ reported significantly higher regret of inaction. Importantly, the conditions (experiential vs. material) were not related to reported "closeness" to recipients of the gifts $(r=.08, p=$ $.42)$ nor the level of closeness to the type of regrets reported $(r=-.15, p=.12)$. These results show that the suggested pattern of regrets by Rosenzweig and Gilovich (2012) for purchases for self-consumption extends to gift giving; people were more likely to report regret of inaction while thinking about experiential gifts and regret of action when thinking about material gifts they have given.

\section{Study 2}

\section{Method}

One hundred and twenty-five participants were recruited from an online pool $\left(57 \%\right.$ female; $\left.M_{\text {Age }}=27.18, S D=5.84\right)$ and were randomly assigned to read either an experiential $(N=63)$ or material $(N=62)$ gift purchases scenarios:

Imagine two people - John, who gave a [new iPod Shuffle $(\$ 55) /$ ticket to a rock concert $(\$ 55)]$ as a gift but now wishes he hadn't, and Robert, who chose not to give a [new iPod Shuffle $(\$ 55) /$ ticket to a rock concert] as a gift but now wishes he had. 
Participants were then asked to indicate which one of the individuals will be more likely to regret his action, using a Likert scale ranging from 1 (the person who acted) to 7 (the person who failed to act). To rule out possible effects of the desirability of receiving the specified gifts, ${ }^{1}$ we measured how much participants would enjoy if they had received the gift, on a scale ranging from 1 (not at all) to 7 (extremely).

\section{Results and Discussion}

A one-way ANCOVA controlling for age $(F[1,121]=.39, p=.53)$ and gender $(F[1,121]=.01, p=.93)$ did show a significant difference in terms of regret $(F[1,121]=17.5, p<.001)$. Specifically, participants in the material condition reported that buyer's remorse would be more salient than the regret which resulted from missed opportunity to buy the iPod ( $M=3.06)$, onesample $t(61)$ against the midpoint value of $4(p<.001)$. However, participants in the experiential condition reported that regret of inaction for the concert ticket gift would be more noticeable $(M=4.54)$, one-sample $t(62)$ compared to the midpoint value of $4(p=.02)$. Importantly, the difference in ratings on the regret scale between the two groups of participants was significant, $t(123)=4.25, p<.001$. Moreover, there was no difference in the level of expected enjoyment (desirability) reported by participants for receiving the iPod $(M=4.80)$ versus the concert ticket $(M=4.49), p>.20$. Also, the effect of gift condition (experiential vs. material) remained unchanged when we controlled for the desirability of the iPod or concert ticket, $B=1.54$, $t(123)=4.42, p<.001$.

\section{Study 3}

To conduct a controlled test of our suggested mechanism (subjective economic value), we used pre-specified gifts in a gift buying scenario to avoid the possibility that participants in either material or experiential treatment would think of different gifts varying in desirability.

\section{Method}

One hundred and seven participants from an online pool (49\% female; $\left.M_{\text {Age }}=26.83, S D=4.93\right)$ were randomly assigned to either material $(N=52)$ or experiential $(N=55)$ condition and read the following text:

We want you to imagine you are deciding on a gift you want to give to someone. You are trying to decide whether to buy and give

\footnotetext{
${ }^{1}$ We used the same products as Rosenzweig and Gilovich (2012).
} 
a [coffee maker machine/half-day coffee brewing training session]. Now, consider two types of regret; buying the [coffee maker machine/half-day coffee brewing training session] and wishing you had not or not buying it and wishing you had.

Participants were then asked to indicate which regret would be more salient on a scale ranging from 1 (buying the [coffee machine/coffee brewing training session]) to 7 (not buying the [coffee machine/coffee brewing training session]). Next, to measure the subjective economic value of the gifts, they answered two questions adapted from Van Boven and Gilovich (2003): "To what extent would you say this gift would be money well-spent?" and, "To what extent do you think the money spent on this gift would have been better spent on something else - some other type of gifts that would make recipient happier?" on scales ranging from 1 (not at all) to 7 (very much).

\section{Results and Discussion}

Two ANCOVA tests controlling for age and gender (all $F^{\prime}$ s $<1$ and $P^{\prime} \mathrm{s}>.80$ ) showed that there was a main effect of condition (experiential vs. material) on the type of regret $(F[1,103]=15.61, p<.001)$ and SEV $(F[1,103]=16.24, p<.001)$. Participants who read about the "coffee brewing training session" as a gift anticipated that the regret of inaction would be stronger $(M=4.75)$ than did those who read about the "coffee machine" as a gift $(M=3.40), t(105)=-4.03, p<.001$. Additionally, compared to participants in material condition $(M=3.35)$, those in experiential condition $(M=4.47)$ reported greater SEV attached to the gift $t(105)=-4.11, p<.001$. To examine the mediating role of SEV on the relationship between type

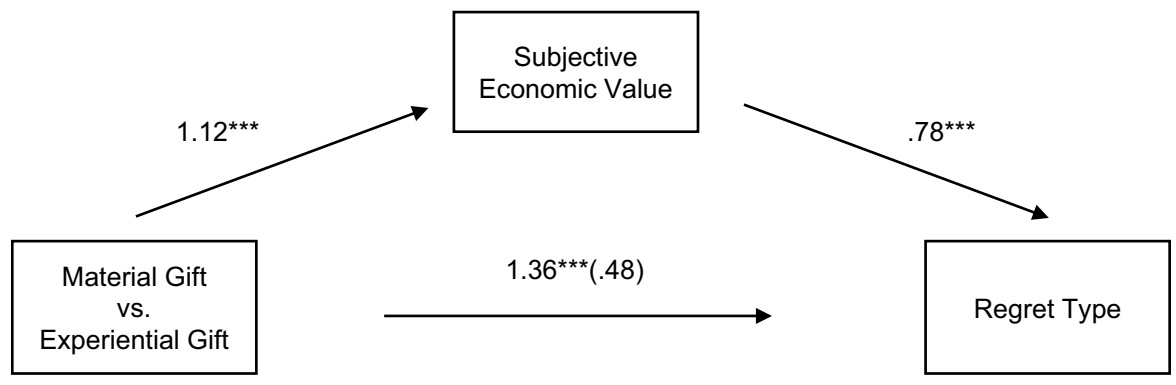

Figure 1: The mediating role of SEV on the relationship between type of gift and type of regret. The unstandardized beta in parentheses reflects the value when the mediator is included in the regression. ${ }^{* * *} p<.001$. Material condition was coded by 0 and experiential condition was coded by 1 . 
of gift and type of regret, we conducted a medication analysis using the Hayes PROCESS macro (material condition was coded as 0 and experiential condition was coded as (1). This model supported mediation (see Figure 1) by demonstrating that (a) experiential gifts were associated with greater SEV $(B=1.12, t=4.11, p<.001)$, (b) greater SEV was associated with increased regret of inaction $(B=.78, t=8.25, p<.001)$, and $(c)$ there was not a significant direct path after entering the mediator into the model $(B=.48, t=1.70, p=.09)$.

\section{Conclusion}

In this study we replicated and extended the findings of Rosenzweig and Gilovich (2012). We replicated their results by showing that people are more likely to experience regret of action for material purchases and regret of inaction for experiential purchases (gifts). In addition, we extended their results by illustrating a possible alternative mechanism (Subjective Economic Value) to "interchangeability" - proposed by authors in the original paper — as the mediating factor on type of regret consumers' experience. We predicted and showed that this occurs because compared to material gifts, people associate experiential gifts with "money better spent" which makes the recipient "happier", hence increasing the likelihood of feeling the regret of inaction (by gift givers) if they fail to give an experiential gift. The SEV measured both the worthiness of the gift in terms of economic value and the joy it may bring for a recipient. The SEV is a key here because if a gift giver feels the money spent on the gift was not worth it, intuitively he or she will experience a greater "buyer's remorse" (which is heightened in material gifts). When it comes to experiential gifts, the "missed opportunity" would be more salient, because the gift giver may realize that the experiential gift (that they failed to give) would have probably provided the recipient with more enjoyment (one of the facets of SEV measure).

While our replication study clearly supports the main findings of Rosenzweig and Gilovich (2012) experiments, and provides evidence for the suggested alternative mechanism (SEV), it also offers future potential avenues of research. First, as the results of study 1 suggest, the closeness of gift giver and the recipient did not affect the type of regret people experienced. It is worthwhile to explore whether the type of regret (action vs. inaction) influences the relationship after giving the gift. Second, it would be interesting to examine whether highlighting the fact that experiential products are tied to a greater SEV (a better monetary expenditure that makes the recipient happier) will increase the willingness of gift givers to give more experiential gifts. Third, it would be of interest to marketers to see whether highlighting the experiential aspects of material gifts would affect the post-purchase regret (by gift givers). 
Lastly, it would be interesting to explore how experiential and material gifts differ in terms of their appropriateness for the recipient and whether such differences influence the post-purchase evaluation of gift givers and recipients.

\section{References}

Dunn, Elizabeth W., Daniel T. Gilbert, and Timothy D. Wilson (2011), "If Money Doesn't Make You Happy, then You Probably Aren't Spending it Right," Journal of Consumer Psychology, 21(2), 115-25.

Guevarra, Darwin A. and Ryan T. Howell (2015), "To Have in Order To Do: Exploring the Effects of Consuming Experiential Products on Well-being," Journal of Consumer Psychology, 25(1), 28-41.

Rosenzweig, Emily and Thomas Gilovich (2012), "Buyer's Remorse or Missed Opportunity? Differential Regrets for Material and Experiential Purchases," Journal of Personality and Social Psychology, 102(2), 215.

Van Boven, Leaf and Thomas Gilovich (2003), "To Do or to Have? That is the Question," Journal of Personality and Social Psychology, 85(6), 1193.

Zeelenberg, Marcel and Rik Pieters (2007), "A Theory of Regret Regulation 1.0," Journal of Consumer Psychology, 17(1), 3-18. 